\title{
Pengaruh pengetahuan perempuan pasangan usia subur terhadap upaya melakukan deteksi dini kanker serviks
}

\author{
Nurul Soimah* \\ Program Studi Kebidanan Program Profesi Bidan, Universitas 'Aisyiyah Yogyakarta, \\ Yogyakarta - Indonesia
}

\begin{abstract}
Cervical cancer is a malignant disease that attacks the female uterine organ. Data of Health Office D.I. Yogyakarta 2014 show that most cancer sufferers come from age 25 -64 years, adolescents 15-24 years, The study was conducted in order to know the effect of knowledge on women of childbearing age efforts to conduct early detection of cervical cancer, the explanatory research design of The One Group Pretestposttest Design experimental study without a control group. The study population in the Aisyiyah recitation group 'Aisyiyah Hamlet Ganggom, Bangunkerto, Turi, Sleman, the total population of 31 people, sampling techniques in total sampling, obtained a sample of 26 respondents who have met the inclusion criteria of women of reproductive age 20-35, educated at least graduated from junior high school, data collection using the adoption questionnaire from Setianingsih and Soimah, (2017), univariate analysis calculated percentage, bivariate using Wilcoxon test. The highest age characteristics of 20-30 years old amounted to $14(53.8 \%)$ respondents, Educational factors most of the last high school education totaled 19 people (73\%), the highest level of knowledge before counseling was 14 people $(53.8 \%)$. after counseling, knowledgeable EFAs were increasing to 21 people $(80.8 \%)$. Wilcoxon test knowledge of pre and post counseling with prevention efforts obtained with a value of $p=1.34>\alpha(0.05)$ can be concluded that there is no effect of counseling on knowledge of EFA to changes in the behavior of prevention of early cervical cancer.
\end{abstract}

Keywords: knowledge; early detection of cervical cancer

Kanker serviks adalah penyakit keganasan yang menyerang organ uterus perempuan Data Dinkes D.I. Yogyakarta 2014, menunjukkan, penderita kanker terbanyak berasal dari usia 25 -64 tahun, usia remaja 15-24 tahun. Penelitian dilakukan agar diketahui pengaruh pengatahuan terhadap upaya wanita usia subur (WUS) untuk melakukan deteksi dini kanker serviks, desain penelitian studi eksperimen The One Group Pretest-posttest Design tanpa kelompok kontrol. Populasi penelitian pada kelompok jama'ah pengajian 'Aisyiyah Dusun Ganggom, Bangunkerto, Turi, Sleman, jumlah populasi 31 orang, teknik sampling secara total sampling, didapatkan sampel 26 responden yang telah memenuhi kriteria inklusi wanita usia reproduksi 20-35, berpendidikan minimal tamat SMP, pengambilan data menggunakan kuisioner yang di adopsi dari penelitian Setianingsih dan Soimah, (2017). Analisis univariat dihitung prosentase, bivariat menggunakan Wilcoxon test. Hasil karakteristik umur tertingi berumur 20-30 tahun sejumlah 14 (53,8\%) responden. Faktor pendidikan sebagian besar pendidikan terakhir SMA berjumlah 19 orang $(73 \%)$, tingkat pengetahuan sebelum penyuluhan berpengetahuan sedang paling banyak yaitu 14 orang $(53.8 \%)$. setelah penyuluhan, pasangan usia subur (PUS) yang berpengetahuan sedang meningkat menjadi 21 orang $(80.8 \%)$. uji Wilcoxon pengetahuan pre dan post penyuluhan dengan

*Korespondensi Penulis: Nurul Soimah (email: nurul.soimah111169@gmail.com), Jl. Siliwangi (Ring Road Barat) No. 63 Mlangi, Nogotirto, Gamping, Sleman, Yogyakarta. 55292. 
upaya pencegahan didapatkan dengan nilai $p=1,34>\alpha(0,05)$ dapat disimpulkan bahwa tidak ada pengaruh penyuluhan pada pengetahuan pasangan usia subur (PUS) terhadap perubahan perilaku pencegahan deteksi dini kanker serviks.

Kata Kunci: pengetahuan; deteksi dini kanker serviks

\section{Pendahuluan}

Penyakit kanker rahim masih menjadi isu serius di masyarakat, hal ini dikarenakan masih didapatkannya angka kejadian kanker rahim yang makin meningkat. Tanggung jawab tenaga kesehatan adalah bagaimana menekan dan menurunkan faktor resiko pada tahap promotif dan kuratif, faktor promotif berkontribusi berarti melalui peningkatan pengetahuan masyarakat secara berkelanjutan tanpa diskriminasi,

Sasaran utama dari upaya pencegahan dan penurunan angka kejadian kanker rahim adalah seluruh lapisan masyarakat sebagaimana diamanahkan oleh negara seperti yang yang tercantum dalam Undang-Undang Nomor 36 Tahun 2009, tentang Kesehatan disebutkan pada muqadimah menimbang bahwa setiap kegiatan dalam upaya untuk memelihara dan meningkatkan derajat kesehatan masyarakat yang setinggitingginya dilaksanakan berdasarkan prinsip non diskriminatif, partisipatif, dan berkelanjutan dalam rangka pembentukan sumber daya manusia Indonesia, serta peningkatan ketahanan dan daya saing bangsa bagi pembangunan nasional. Perundangan ini sebagai salah satu bentuk ketegasan pemerintah pada upaya pembangunan manusia meuju bangsa yang sehat dan berdaya saing.

Data Dinas Kesehatan (Dinkes) Daerah Istimewa Yogyakarta (2014) jumlah kasus kanker leher rahim sebanyak 104 kasus, surveilans terpadu penyakit tidak menular puskesmas, pada tahun 2014 menunjukkan adanya peningkatan ditiap tahunnya. Selama periode Januari hingga April 2015, angka kesakitan karena kanker serviks yang baru didapatkan 5 orang. Jumlah kasus kanker payudara dan kanker kanker leher rahim (serviks) juga terus mengalami fluktuasi dari tahun ke tahun. Pada 2009, kasus kanker serviks sebanyak 111 dan kanker payudara 191 kasus. Sedangkan pada 2014, untuk periode Januari hingga April, sudah ada 29 kasus payudara dan 5 kasus kanker serviks yang baru (Tim Liputan TribunJogja.com, 2014). Prevalensi penyakit kanker rahim saat ini dipengaruhi oleh beberapa faktor sebagai predisposisi angka kejadian, menurut Dinkes Kab. Sleman (2013) faktor perokok perempuan sebanyak $2,7 \%$.

Data Dinas Kesehatan (Dinkes) Daerah Istimewa Yogyakarta (2014) jumlah kasus kanker leher rahim sebanyak 104 kasus, surveilans terpadu penyakit tidak menular puskesmas, pada tahun 2014 menunjukkan adanya peningkatan ditiap tahunnya. Selama periode Januari hingga April 2015, angka kesakitan karena kanker serviks yang baru didapatkan 5 orang. Data Dinkes DIY menunjukkan, penderita kanker terbanyak berasal dari kalangan usia 25 hingga 64 tahun, ditemukan juga di kalangan usia remaja 15 hingga 24 tahun.

Penelitian terkait masalah kanker serviks telah dihasilkan oleh beberapa penelitian sebelumnya 
seperti penelitian yang dilakukan oleh Dewi, Sawitri, dan Adiputra (2013) di Denpasar didapatkan bahwa salah satu faktor resiko kanker serviks yang dominan adalah disebabkan oleh Perineal Hygiene yang buruk. Jurnal lain terkait masalah pengetahuan PUS tentang deteksi dini kanker serviks seperti yang dihasilkan dari penelitian Setianingsih dan Soimah (2017) didapatkan hasil bahwa pengetahuan wanitia usia subur (WUS) yang baik sejumlah $49,5 \%$, sedangkan upaya pencegahan yang telah dilakukan secara baik sejumlah $17,5 \%$.

Mengacu pada paparan beberapa hasil penelitian tersebut, hal yang perlu diperhatikan adalah dampak kanker serviks yang berpengaruh buruk bagi keselamatan seseorang, paparan data dari pusat data kementrian kesehatan republik Indonesia tahun 2015 didapatkan dari rumah sakit Darmais bahwa angka kematian akibat kanker serviks sebanyak 65 orang, penyebab kematian dari angka tersebut adalah karena pasien datang dan terdeteksi kanker serviks sudah terdiagnosis kanker dengan stadium lanjut, jurnal lain dipaparkan dari penelitian Sulistiowati, Lolong dan Pangaribuan, (2016) diadapatkan hasil dari keseluruhan data kematian yang terkumpul di 15 kabupaten/kota pada tahun 2011 berjumlah 36.834 , di mana kematian yang disebabkan kanker berjumlah 2433 kasus. Berdasarkan tempat kejadiannya, meninggal karena kanker hampir 2 kali lipat di luar Rumah Sakit (rumah) dibandingkan di rumah sakit dipaparkan bahwa jenis kanker terbanyak yang tercatat di luar fasilitas kesehatan (rumah) adalah 11,2\% kanker serviks.

Kebijakan Pemerintah berperan pada mekanisme pengendalian kanker serviks di Indonesia, secara jelas tertuang dalam UU No. 36 Tahun 2009 tentang Kesehatan pasal 161 ayat (3) disebutkan bahwa manejemen pelayanan kesehatan berupa promotif, preventif, kuratif dan rehabilitatif dititik beratkan pada deteksi dini dan pencegahan penyakit menular seksual. Pentingnya dilakukan skrening deteksi dini kanker serviks merupakan implementasi dari upaya preventif seperti yang telah disebutkan pada pasal tersebut di atas yang perlu diketahui oleh masyarakat.

\section{Metode Penelitain}

Penelitian ini merupakan penelitian explanatory research dengan desain studi eksperimen The One Group Pretest-posttest Design tanpa kelompok kontrol, (Notoatmodjo, 2012). Penelitian dilakukan pada kelompok jama'ah pengajian 'Aisyiyah dusun Ganggom, Bangunkerto, Turi Sleman, jumlah populasi 31 orang, teknik sampling secara total sampling, didapatkan sampel 26 responden yang telah memenuhi kriteria inklusi perempuan usia reproduksi 20-35, berpendidikan minimal tamat SMP, pengambilan data menggunakan kuisioner adops dari Setianingsih dan Soimah (2017). Analisis univariat dihitung prosentase, bivariat menggunakan Wilcoxon test terhadap upaya pencegahan kanker serviks, olah data digunakan aplikasi Microsoft SPSS.

\section{Hasil dan Pembahasan}

Responden terbanyak didapatkan dari kelompok umur produktif yaitu pada rentang dari responden berumur 20-30 tahun sebanyak 14 responden $(53,8 \%)$, responden berumur $31-35$ tahun berjumlah 12 (46,1\%). 
Tabel 1.

Distribusi Frekuensi Karakteristik Umur Responden di Dusun Ganggom, Bangunkerto, Turi Sleman

\begin{tabular}{lccc}
\hline No & Usia & Jumlah & Persentase (\%) \\
\hline 1 & $20-30$ & 14 & 53,8 \\
2 & $31-35$ & 12 & 46,1 \\
\hline \multicolumn{2}{c}{ Total } & 26 & 100 \\
\hline
\end{tabular}

Sumber: Data Primer 2018

Tabel 2.

Distribusi Frekuensi Karakteristik Pendidikan Responden di Dusun Ganggom, Bangunkerto, Turi Sleman

\begin{tabular}{cccc}
\hline No & Pendidikan & Frekuensi (f) & Presentase (\%) \\
\hline 1. & SMP & 7 & 27 \\
2. & SMA & 14 & 53,8 \\
3. & DIII & 4 & 15,3 \\
4. & S1 & 1 & 3,8 \\
\hline & Total & 26 & 100,0 \\
\hline
\end{tabular}

Sumber: Data Primer, 2018

Kriteria umur responden yang diambil adalah kelompok perempuan pada rentang masa usia produktif, distribusi kelompok umur ini senada dengan jurnal penelitian Rahmadhan, Ade, dan Suyanto (2016) bahwa dari 17 responden dengan rentang usia 26-35 tahun (54.8\%). 11 orang berumur $<26$ tahun (35.5\%) dan 3 orang berumur $>35$ tahun (9.7\%).

Umur produktif merupakan faktor resiko penting pada penyakit kanker serviks, karena pada umur produktif sambungan squamosal kolumner (SSK) berada di daerah terjadi infeksi HPV (Sinclair, 2010), disebutkan juga bahwa faktor lain seperti paritas tinggi, perempuan usia 15-19 tahun juga berpotensi terjadinya angka infeksi karena human papillomavirus sehingga rentan dengan kejadian kanker rahim.

Mengacu pada karakteristik usia responden terlihat bahwa pada rentang usia responden, faktor usia menurut Arikunto (2013) bahwa usia mempengaruhi terhadap daya tangkap dan pola pikir seseorang. Semakin bertambah usia akan semakin berkembang pula daya tangkap dan pola pikirnya.pada rentang usia tersebut seorang perempuan memasuki tingkat kematangan pola pikir, namun belum tentu menjamin daya tangkap yang cepat terhadap respon informasi yang didapatkan, menurut Notoatmodjo (2012) dijelaskan bahwa salah satu tingkat pengetahuan sesorang adalah tahu sebagai kemampuan mengingat suatu materi yang telah dipelajari sebelumnya (recall) terhadap suatu yang spesifik dari seluruh bahan yang dipelajari atau rangsangan yang telah diterima, perubahan tingkat pengetahuan yang didapatkan dari hasil pre dan post yang mengalami perubahan angka secara menyeluruh pada tiap tingkatan, namun dari kategorinya yang tertinggi tetap pada tingkatan sedang, perubahan tersebut terjadi masih sebatas tingkatan tahu tetapi belum sampai pada tingkatan memahami. 
Hasil penelitian menunjukan bahwa dari 26 reponden sebagian besar memiliki pendidikan terakhir SMA berjumlah 14 orang (53,8\%). SI 1 $(3,8 \%)$. Tingkat pendidikan tertinggi diperoleh dari pendidikan SMA.

Berdasarkan Tabel 3 menunjukkan bahwa dari 26 responden sebelum penyuluhan dilakukan PUS yang berpengetahuan sedang paling banyak yaitu 14 orang (53.8\%). Sedangkan setelah penyuluhan dilakukan PUS yang ber- pengetahuan sedang megalami peningkatan paling banyak yaitu 21 orang (80.8\%). yang berpengetahuan baik pada pre 9 orang (34.6\%), menurun pada post menjadi 4 orang (15.4\%).

Didapatkan dari hasil dengan kriteria pengetahuan baik pada saat pre test mengalami penurunan saat post tes menurun menjadi kurang dan meningkat pada kriteria sedang, pada kriteria kurang juga mengalami penurunan sehingga meningkat menjadi berpengetahuan sedang. Hal

Tabel 3.

Distribusi Frekuensi Pengetahuan PUS tentang Deteksi Dini Kanker Rahim sebelum dan setelah Penyuluhan

\begin{tabular}{|c|c|c|c|c|c|}
\hline No & Pengetahuan & Pre & Persentase\% & Post & Persentase\% \\
\hline 1 & Kurang & 3 & 11.5 & 1 & 3.8 \\
\hline 2 & Sedang & 14 & 53.8 & 21 & 80.8 \\
\hline 3 & Baik & 9 & 34.6 & 4 & 15.4 \\
\hline & Total & 26 & 100.0 & 26 & 100.0 \\
\hline
\end{tabular}

Tabel 4.

Hasil Uji Statistik Wilcoxon Signed Ranks Test Pengaruh Pengetahuan Perempuan Pasangan Usia Subur terhadap Upaya Melakukan Detksi Dini Kanker Serviks

\begin{tabular}{llllll}
\hline $\begin{array}{l}\text { Pengetahuan } \\
\text { Remaja }\end{array}$ & $\mathrm{N}$ & $\begin{array}{l}\text { Mean } \\
\text { Rank }\end{array}$ & $\begin{array}{l}\text { Sum of } \\
\text { Ranks }\end{array}$ & $\mathrm{Z}$ & $\begin{array}{l}\text { Asymp. Sig. (2- } \\
\text { tailed) }\end{array}$ \\
\hline $\begin{array}{l}\text { Negative Ranks } \\
\text { Positive Ranks }\end{array}$ & 6 & 5.00 & 30.00 & $-1.000^{\mathrm{b}}$ & .317 \\
Ties & 3 & 5.00 & 15.00 & & \\
\hline Total & 17 & & & \\
\hline \multicolumn{7}{c}{ Sumber: Data Primer 2018 }
\end{tabular}

Tabel 5.

Hasil Uji Statistik Wilcoxon Signed Ranks Test Perubahan Upaya Melakukan Detksi Dini Kanker Serviks

\begin{tabular}{llllll}
\hline $\begin{array}{l}\text { Perubahan } \\
\text { Perilaku }\end{array}$ & N & $\begin{array}{l}\text { Mean } \\
\text { Rank }\end{array}$ & $\begin{array}{l}\text { Sum of } \\
\text { Ranks }\end{array}$ & Z & $\begin{array}{l}\text { Asymp. Sig. (2- } \\
\text { tailed) }\end{array}$ \\
\hline $\begin{array}{l}\text { Negative Ranks } \\
\text { Positive Ranks }\end{array}$ & 4 & 6.50 & 26.00 & -1.500 &, 134 \\
Ties & 13 & 7.22 & 65.00 & & \\
\hline Total & 26 & & & \\
\hline \multicolumn{7}{l}{ Sumber: Data Primer 2018 }
\end{tabular}


ini terjadi karena faktor pengetahuan yang belum bisa memahami secara keseluruhan tentang tanda gejala dan penyebab terjadinya kanker rahim dan bagaimana cara deteksi dini yang benar. Hasil uji statistik Wilcoxon menujukkan bahwa nilai $p$ value $=0,134$. $>$ dari 0.05 bermakna tidak terdapat hubungan pengaruh pengetahuan terhadap upaya untuk melakukan deteksi dini kanker serviks.

Pengetahuan merupakan salah satu cara agar sesorang tahu dan mau untuk berubah, mengingat bahwa masalah perilaku deteksi dini kanker rahim adalah merupakan upaya awal langkah preventif bahkan kemudian bisa menjadi sarana pencegahan pada pola kebiasaan sehari hari yang tidak sehat, sebagai salah satu tolak ukur kejadian kanker rahim di Yogyakarta telah didapatkan hasil penelitian bahwa skrining faktor risiko kanker leher rahim dengan sejumlah 300 sasaran tercapai 225 sasaran Interpertasi hasil: Kelas I 200 sasaran, Kelas II 23 sasaran, Kelas III 1 sasaran dan Kelas IV 1 sasaran, Angka kejadian kanker serviks di wilayah Daerah Istimewa Yogyakarta (DIY) sebesar 0,42\% perempuan, Riset Kesehatan Dasar (Depkes.go.id, 2014; Dinkes Kab. Sleman, 2013). Data ini merupakan bagaian salah satu wacana tugas yang harus diselesaikan oleh tenaga kesehatan didukung peran serta masyarakat mengacu pada hasil dan permasalahan yang ada di Pemrintahan khususnya Departemen Kesehatan.

Hasil penelitian ini sejalan dengan beberapa jurnal dari peneliti sebelumnya didapatkan hasil yang bervariasi, penelitian Juwita Situmorang, Winarni, dan Mawarni (2016) didapatkan bahwa tidak terdapat hubungan yang bermakna antara pengetahuan dengan perilaku deteksi dini ( $p$ value $=0,054$ ). Sejalan dengan penelitian ini didapatkan oleh Kivistik, Lang, Baili, Anttila, dan Veerus, (2011) bahwa di Brazil, responden memiliki pengetahuan yang kurang tentang HPV. dari analisis ini didapatkan pengetahuan perempuan tentang faktor risiko kanker serviks masih rendah yaitu $70,9 \%$. Hasil senada juga terdapat pada penelitian di Estonia, dimana pengetahuan perempuan tentang faktor risiko dan deteksi dini kanker serviks masih rendah. Jurnal Senada dipaparkan oleh Rahmadhan et al. (2016) dengan hasil uji Spearman diketahui tidak terdapat hubungan yang bermakna antara pengetahuan dan sikap perempuan pekerja seksual tidak langsung tentang Pap smear dan IVA dengan perolehan $p$ value $=0,304$.

Hasil penlitian ini jika dianalogkan antara pengetahuan dan perlilaku secara teori bahwa kedua faktor tersebut memiliki kesamaan pada faktor yang bisa berpengaruh yaitu faktor pendidikan, faktor budaya, faktor ekonomi dan faktor lingkungan sehingga dimungkinkan bahwa tidak adanya pengaruh adalah karena terdapat pengaruh lain yang lebih yang berkontribusi pada uapaya seseorang untuk melakukan upaya melakukan deteksi dini kanker serviks.

Perbedaan hasil penelitian didapatkan dari penelitian Setianingsih dan Soimah (2017) dan Soimah (2018) bahwa terdapat hubungan bermakna antara pengetahuan dan sikap pasangan usia subur terhadap upaya deteksi dini kanker rahim, Secara bermakna bahwa pengetahuan tidak selamanya berpengaruh pada perubahan perilaku tetapi akan dapat menunjukkan adanya korelasi positif pada perubahan tingkat penge- 
tahuan seseorang ketika sudah pernah terpapar dengan informasi hal ini didukung dari penelitian Sulistiowati dan Sirait (2014) yang menyatakan bahwa pengetahuan perempuan tentang kanker serviks rendah (82,7\%). jika dianalogkan antara pengetahuan dan pengaruhnya terhadap perilaku pencegahan, maka informasi menjadi bermakna dan masih diperlukan peran prefentif dari tenaga kesehatan untuk lebih proaktif melakukan pendidikan kesehatan agar masyarakat sadar akan bahaya kanker perlu dilakukan secara lebih intensif mengingat bahwa dampak yang diakibatkan oleh penyakit kanker serviks agar masyarakat sadar akan bahaya kanker, sehinnga upaya pencegahan terjadinya keterlambatan bisa berkurang, namun demikian peningkatan pengetahuan menjadi kurang berarti jika penyebab terjadinya bahaya kanker serviks tidak diikuti dengan tindakan prefentif lain.

Pengetahuan dapat dipengaruhi oleh faktor beberapa faktor diantaranya adalah faktor informasi dan faktor pendidikan. Tingkat pendidikan tertinggi diperoleh dari pendidikan SMA, pada tingkat tersebut sudah masuk pada kategori tingkat pendidikan sedang sehingga seseorang pada tingkat ini sudah pernah terpapar informasi minimal tentang pendidikan sek sehat dan akibat sek bebas yang merupakan salah satu program penyuluhan sek di sekolah tingkat SMA (Fitriani \& Sarwinanti, 2013).

Pengetahuan responden tentang kanker rahim pada saat pre penyuluhan masih sebatas tahu apa itu kanker secara umum, sedangkan gejala secara pasti dan gambaran umum kanker serviks belum dapat dijabarkan secara kualitatif dengan jelas dan benar. Hasil penelitian ini sejalan dengan penelitian yang didapatkan oleh Rahmadhan et al. (2016) yang memaparkan bahwa Mayoritas responden memiliki tingkat pendidikan terakhir Sekolah Menengah Atas (SMA) yaitu sebanyak 12 orang (38.7\%). Adapun dari faktor informasi berdasarkan pada hasil yang didapatkan bahwa, seluruh responden sebelum adanya penelitian ini sudah pernah mendapatkan informasi tentang vaksinasi untuk pencegahan kanker serviks dari sales yang menawarkan secara door to door didusun pada tahun 2015. Hasil penelitian ini sejalan dengan penelitian yang telah dilakukan oleh Lestari, Syaifudin, dan Ismarwati (2016) di kelurahan Kota baru wilayah kerja Puskesmas Gondokusuman II Yogyakarta menunjukan bahwa ada hubungan yang signifikan antara pengetahuan pada perempuan usia subur dengan partisipasi deteksi dini kanker serviks dengan nilai $p$-value $=0,020$ hal tersebut disebabkan karena perempuan yang memiliki pengetahuan kurang atau cukup cenderung tidak partisipasi deteksi dini berpartisipasi, hal ini dikarenakan kurangnya informasi mengenai cara pencegahan dan deteksi dininya serta kurangnya tingkat kewaspadaan perempuan usia subur terhadap kanker serviks.

Peran penyuluhan sebagai salah satu model pendidikan non Formal yang diharapkan dapat meningkatkan pengetahuan seseorang, upaya peningkatan tingkat pengetahuan tentang kesehatan reproduksi merupakan salah satu upaya tenaga kesehatan mewujudkan amanat pemerintah Republik Indosnesi mengacu pada kaidah hukum di Indonesia sebagaimana disebutkan dalam dalam perudangan negara Republik Indonesia diantanya disebutkan dalam Undang- 
Undang 17 tahun 2007 tentang Rencana Pembangunan Jangka Panjang Nasional tahun 20052025 pada ponit menimbang disebutkan bahwa Indonesia memerlukan perencanaan pembangunan jangka panjang sebagai arah dan prioritas pembangunan secara menyeluruh yang akan dilakukan secara bertahap untuk mewujudkan masyarakat adil dan makmur sebagaimana diamanatkan oleh Undang-Undang Dasar Negara Republik Indonesia Tahun 1945; Selanjutnya dijelaskan pada pasal 3 bahwa RPJP Nasional merupakan penjabaran dari tujuan dibentuknya Pemerintahan Negara Indonesia yang tercantum dalam Pembukaan Undang-Undang Dasar Negara Republik Indonesia Tahun 1945, yaitu untuk melindungi segenap bangsa dan seluruh tumpah darah Indonesia, memajukan kesejahteraan umum, mencerdaskan kehidupan bangsa, dan ikut melaksanakan ketertiban dunia yang berdasarkan kemerdekaan, perdamaian abadi, dan keadilan sosial dalam bentuk rumusan visi, misi dan arah Pembangunan Nasional.

Perudangan tersebut merupakan salah satu pedoman, tujuan dan arah tugas bagi tenaga kesehatan dapat mewujudkan peran, tugas sesuai dengan wewenangnya, yang selanjutnya diperlukan dukungan dan kesiapan dari masyarakat sebagai perwujudan dari pelaksanaan amanat Undang- Undang. Mengacu pada jawaban tertinggi dari kuisioner yang diisi oleh responden tentang pengetahuan pada akses fasilitas layanan kesehatan dan kepada siapa bisa melakukan deteksi dini kanker rahim, didapatkan bahwa responden telah tahu bisa menggunakan fasilitas BPJS dan bisa periksa oleh bidan di Puskesmas. Pengetahuan tersebut benar sesuai dengan ketentuan pemerintah sebagai regulasi yang dapat membantu masyarakat pada akses layanan kesehatan reproduksi, regulasi tersebut dengan jelas telah diatur dalam Peraturan Badan Penyelenggara Jaminan Sosial Kesehatan Nomor 1 Tahun 2014 tentang Penyelenggaraan jaminan Kesehatan Bagian Ketujuh, Pasal 73, ayat 2 dan point (c); Pelayanan Skrining Kesehatan.

Pasal 73: Pelayanan skrining kesehatan sebagaimana dimaksud pada ayat (1) ditujukan untuk mendeteksi risiko penyakit dan mencegah dampak lanjutan dari risiko penyakit tertentu meliputi: kanker leher rahim; ayat (6) Pelayanan skrining kesehatan sebagaimana dimaksud pada ayat (2) huruf c sampai dengan huruf e dilakukan sesuai dengan indikasi medis.

Pasal 53: Pemberian pelayanan kesehatan oleh Bidan dan Perawat dalam hal suatu kecamatan tidak terdapat dokter sebagaimana dimaksud pada ayat (1) meliputi pelayanan bidan dan perawat dengan cakupan pelayanan bidan dan perawat sesuai dengan kompetensi dan kewenangannya.

\section{Kesimpulan}

Tingkat pengetahuan dari 26 responden sebelum penyuluhan dilakukan PUS yang berpengetahuan sedang paling banyak yaitu 14 orang (53.8\%). Sedangkan setelah penyuluhan dilakukan PUS yang berpengetahuan sedang mengalami peningkatan paling banyak yaitu 21 (80.8\%). Sedangkan pada upaya Pre tertinggi pada kategori sedang sejumlah 13 (50\%),Upaya post kategori sedang sejumlah 13 orang (50\%), meningkat pada kategori post upaya baik dari 9 orang menjadi 12 orang, Analisis dengan uji Wilcoxon pengetahuan pre dan post penyuluhan 
dengan nilai $p=.317<\alpha(0,05)$ sebagaimana ditunjukkan pada tabel di atas, maka dapat disimpulkan bahwa tidak ada pengaruh pengetahuan PUS terhadap perubahan perilaku pencegahan deteksi dini kanker rahim.[]

\section{Daftar Pustaka}

Arikunto, S. (2013). Prosedur Penelitian Suatu Pendekatan Praktik. Jakarta: Rineka Cipta.

Depkes.go.id. (2014). Profil Kesehatan Provinsi DIY 2014. Diambil dari http://www.depkes. go.id/resources/download/profil/PROFIL_KA B_KOTA_2014/3471_DIY_Kota_Yogyakarta_ 2014

Dewi, I. G. A. A. N., Sawitri, A., \& Adiputra, I. N. (2013). Paparan asap rokok dan higiene diri merupakan faktor risiko lesi prakanker leher rahim di Kota Denpasar tahun 2012. Public Health and Preventive Medicine Archive, 1(1), 163. https://doi.org/10.15562/phpma. v1i1.163

Dinkes Kab. Sleman. (2013). Profil Kesehatan Kab. Sleman. Diambil dari dinkes. slemankab. go.id/wp-content/uploads/.../PROFIL2013.pdf

Fitriani, F., \& Sarwinanti, S. (2013). Pengaruh penyuluhan kesehatan reproduksi terhadap sikap dampak seks bebas siswa kelas $X$ usia 15-17 tahun di sekolah MAN Cendekan Bantul 2013. Universitas 'Aisyiah Yogyakarta, Yogyakarta. Diambil dari http://lib. unisayogya.ac.id

Juwita Situmorang, M., Winarni, S., \& Mawarni, A. (2016). Hubungan pengetahuan dan sikap dengan perilaku deteksi dini kanker di RSUP Kariadi Semarang tahun 2015. Jurnal Kesehatan Masyarakat, 4(1), 2356-3346.
Diambil dari http://ejournal-s1.undip.ac.id/ index.php/jkm

Kivistik, A., Lang, K., Baili, P., Anttila, A., \& Veerus, P. (2011). Women's knowledge about cervical cancer risk factors, screening, and reasons for non-participation in cervical cancer screening programme in Estonia. $B M C$ Women's Health, 11(1), 43.

Lestari, M. A., Syaifudin, S., \& Ismarwati, I. (2016). Hubungan pengetahuan dan sikap WUS dengan perilaku melakukan pemeriksaan IVA di Kelurahan Kotabaru Wilayah Kerja Puskesmas Gondokusuman II Yogyakarta. Yogyakarta. Diambil dari http://digilib2. unisayogya.ac.id/xmlui/handle/123456789/ 2112

Notoatmodjo, S. (2012). Promosi Kesehatan dan Ilmu Perilaku. Jakarta: Rineka Cipta.

Rahmadhan, R., Ade, W., \& Suyanto, S. (2016). Hubungan pengetahuan dan sikap terhadap tindakan Wanita Pekerja Seksual tidak langsung tentang Pap Smear dan Iva sebagai deteksi dini kanker serviks di Hotspot X Kecamatan Payung Sekaki Pekanbaru. Jom FK (Vol. 3). Universitas Riau.

Setianingsih, F., \& Soimah, N. (2017). Hubungan pengetahuan WUS tentang deteksi dini kanker serviks dengan upaya pencegahan yang dilakukan WUS. Universitas 'Aisyiyah Yogyakarta, Yogyakarta. Diambil dari http://lib.unisayogya.ac.id

Sinclair, C. (2010). Buku saku bidan. Jakarta: EGC Penerbit Buku Kedokteran.

Soimah, N. (2018). Pengetahuan pasangan usia subur tentang deteksi dini kanker rahim dan akses layanan pemeriksaan IVA/ Papsmear. Jurnal Kebidanan dan Keperawatan Aisyiyah, 13(2), 150-161. https://doi.org/10.31101/ jkk.398 
Sulistiowati, E., Lolong, D. B., \& Pangaribuan, L. (2016). Gambaran penyebab kematian karena kanker di 15 kabupaten/kota, Indonesia tahun 2011. Buletin Penelitian Sistem Kesehatan, 19(2), 19-125. Diambil dari https://media.neliti.com/media/publications /63563-ID-gambaran-penyebab-kematiankanker

Sulistiowati, E., \& Sirait, A. M. (2014). Pengetahuan tentang faktor risiko, perilaku dan deteksi dini kanker serviks dengan Inspeksi Visual
Asam Asetat (IVA) pada wanita di Kecamatan Bogor Tengah, Kota Bogor. Buletin Penelitian Kesehatan, 42(3), 193-202. Diambil dari http://ejournal.litbang.kemkes. go.id/index.php/BPK/article/view/3632

Tim Liputan TribunJogja.com. (2014, Juli 3). Kasus kanker di DIY tertinggi nasional. Tribunjogja.com. Diambil dari https://jogja. tribunnews.com/2014/07/03/kasus-kankerdi-diy-tertinggi-nasional 